\title{
Optimal experimental design for estimating the kinetic parameters of processes described by the first-order Arrhenius model under linearly increasing temperature profiles
}

\author{
Luís M. Cunha ${ }^{a}$, Fernanda A.R. Oliveira ${ }^{b, *}$ \\ ${ }^{a}$ Escola Superior de Biotecnologia, Universidade Católica Portuguesa, Rua Dr. António Bernardino de Almeida, 4200 Porto, Portugal \\ ${ }^{\mathrm{b}}$ Department of Food Engineering, University College Cork, Cork, Ireland
}

\begin{abstract}
The optimum experimental design for systems following the first-order Arrhenius model under linearly increasing temperature profiles was studied by determining the sampling conditions that lead to a minimum confidence region of the model parameters. It was found that experiments should be started at the lowest possible temperature and, for each initial temperature, there is an optimal heating rate. This heating rate is often too high to be feasible, implying that experiments have to be conducted at a lower practicable heating rate. In this situation the experiments should be replicated in order to improve the precision of the estimates. If both the initial temperature and the heating rate are fixed at their optimal values, the optimal sampling times correspond to fractional concentrations that are irrational numbers (approximately 0.70 and 0.19 ) whose product is exactly $1 / e^{2}$, as earlier found for the Bigelow model. A case study based on the estimation of the kinetic parameters of the acid hydrolysis of sucrose is also presented.
\end{abstract}

Keywords: Acid sucrose hydrolysis; Confidence regions; $D$-optimal design; Non-isothermal conditions; Parameter precision

\section{Introduction}

First-order reaction kinetics are widely used for describing chemical and microbiological changes in food processing and storage. When the effect of temperature is to be assessed, the so-called Arrhenius and Bigelow models are the most common. Both rely on first-order type kinetics. Several researchers that have compared the two models suggested that both fit experimental kinetic data well (Jonsson, Snygg, Härnulv \& Zacrisson, 1977; Manji \& van de Voort, 1985; Ramaswamy, van de Voort \& Ghazala, 1989; David \& Merson, 1990; Ocio, Fernandez, Alvarruiz \& Martínez, 1994; Saraiva, Oliveira, Hendrickx, Oliveira \& Tobback, 1996). In spite of the never-ending discussion about the relative merits of each model, both are empirical and the variability of most kinetic data does not allow to distinguish between the quality of the fit of the two models (Holdsworth, 1985).

\footnotetext{
${ }^{*}$ Corresponding author. Tel.: +353-21-490-2383; fax: +353-21-4270249.

E-mail address: faroliveira@ucc.ie (F.A.R. Oliveira).
}

Methods for estimation of kinetic parameters may be broadly divided into constant and varying-conditions methods, in the case of temperature, isothermal and non-isothermal methods. The isothermal analysis of kinetic data involves a considerable amount of experimental work at constant temperatures under a specific range of interest, resulting in an expensive and timeconsuming procedure. An additional problem may arise if the parameter estimates correspond to a biased solution, that is, although yielding a good fit to the experimental data are actually quite different from the true values. In this situation, when they are used for predicting processes under non-isothermal conditions, they may lead to significant deviations (Van Loey, 1996). However, isothermal methods are necessary for assessing the dependency of the kinetic parameters on temperature. Most of the kinetic parameters reported in literature were estimated by regression of experimental data obtained with isothermal experiments.

Non-isothermal methods, on the other hand, are based on a single experiment in which temperature and the factors under study are recorded as function of time. Thus, kinetic parameters are evaluated from a 


\begin{tabular}{|c|c|c|c|}
\hline \multicolumn{2}{|c|}{ Nomenclature } & $T_{i}$ & temperature for the $i$ th experiment $\left({ }^{\circ} \mathrm{C}\right)$ \\
\hline \multirow[t]{2}{*}{$C_{i}$} & number or concentration of a component or quality factor at & $T_{0}$ & initial temperature $\left({ }^{\circ} \mathrm{C}, \mathrm{K}\right)$ \\
\hline & time $t_{i}$ & $T_{\text {ref }}$ & reference temperature $\left({ }^{\circ} \mathrm{C}, \mathrm{K}\right)$ \\
\hline \multirow[t]{2}{*}{$C_{0}$} & number or concentration of a component or quality factor at & $t$ & time (min) \\
\hline & time $t=0$ & $t_{i}$ & sampling time for the $i$ th experiment (min) \\
\hline$D_{\mathrm{T}}$ & decimal reduction time at a given temperature $T(\min )$ & $z$ & thermal death time parameter $\left({ }^{\circ} \mathrm{C}\right)$ \\
\hline$E_{\mathrm{a}}$ & activation energy $\left(\mathrm{kJ} \mathrm{mol}^{-1}\right)$ & \multicolumn{2}{|c|}{ Greek symbols } \\
\hline $\mathbf{F}$ & matrix of the derivatives of the response function in order to & $\Delta$ & modulus of the determinant of $\mathbf{F}\left(\min ^{-1}\right.$ or $\left.\min ^{-1}{ }^{\circ} \mathrm{C}^{-1}\right)$ \\
\hline$k_{\text {ref }}$ & reaction rate constant at a reference temperature $T_{\text {ref }}\left(\min ^{-1}\right)$ & $\Delta_{\max }$ & $\begin{array}{l}\text { modulus of the determinant of } \mathbf{F} \text { for a fixed temperature } \\
\text { profile }\left(\min ^{-1}{ }^{\circ} \mathrm{C}^{-1}\right)\end{array}$ \\
\hline $\begin{array}{l}k_{\mathrm{T}} \\
m\end{array}$ & $\begin{array}{l}\text { reaction rate constant at the temperature } T\left(\min ^{-1}\right) \\
\text { heating rate }\left({ }^{\circ} \mathrm{C} \min ^{-1}\right)\end{array}$ & $\Delta_{\mathrm{opt}}$ & modulus of the determinant of $\mathbf{F}$ for optimal experimental \\
\hline$m_{\mathrm{opt}}$ & heating rate for optimal parameter estimation $\left({ }^{\circ} \mathrm{C} \min ^{-1}\right)$ & & $\begin{array}{l}\text { conditions }\left(\mathrm{min}^{-1}{ }^{0} \mathrm{C}^{-1}\right) \\
\text { fractional concentration for the } i \text { th experiment }\end{array}$ \\
\hline$n$ & number of experimental points & $\theta$ & vector of $p$ parameters \\
\hline $\begin{array}{l}p \\
R\end{array}$ & $\begin{array}{l}\text { number of parameters } \\
\text { ideal gas constant }\left(\mathrm{kJ} \mathrm{mol}^{-1} \mathrm{~K}^{-1}\right)\end{array}$ & $\zeta$ & efficiency factor $\left[\zeta=\Delta_{\max } / \Delta_{\mathrm{opt}} \times 100\right](\%)$ \\
\hline$T$ & temperature $\left({ }^{\circ} \mathrm{C}, \mathrm{K}\right)$ & & \\
\hline
\end{tabular}

single test covering the desired temperature range. These methods have significant advantages: minimisation of experimental requirements, overcoming thermal lag problems and providing a dynamic situation closer to the reality of most thermal processes. Of course, they require the previous knowledge of the functional relationship between the kinetic parameters and temperature. The use of non-isothermal methods was first introduced by Rogers (1963) and has been reported for the Arrhenius model (Rhim, Nunes, Jones \& Swartzel, 1989a,b; Nunes, Rhim \& Swartzel, 1991). Moreira, Oliveira, Silva and Oliveira (1993) compared isothermal and non-isothermal methods for estimation of the parameters of a mass diffusion model with an Arrhenius type temperature dependency. Non-isothermal methods may use different temperature programming methods, as reviewed by Rhim et al. (1989a). They can be classified as: (i) non-linear temperature programs (hyperbolic, logarithmic, exponential, linearly increasing inverse absolute temperature, etc.) and (ii) linear temperature programs. The later are the most commonly used because the temperatures have the same weight in the calculation of the kinetic parameters. Additionally, most of the software related to time-temperature programs allows constant heating rates only.

The experimental design for non-isothermal methods under linearly increasing temperature requires the definition of the initial and final temperature and of the heating rate, as well as sampling times. Most of the researchers select the initial and final temperatures so that the range of temperatures of interest is covered, the heating rate is mostly dictated by the capabilities of the available equipment, and sampling times are usually defined according to heuristic designs. It was however shown that parameter estimation is quite sensitive to the sampling times and particularly to the heating rate used (Brandão \& Oliveira, 1997).

The influence of the experimental design on parameter estimation has long been recognised. Box and Lucas
(1959) proposed an optimum design criterion for nonlinear models, based on establishing the sampling conditions that lead to a minimum confidence region, for a standard situation of a number of observations $(n)$ equal to the number of parameters $(p)$, which is also known as the $D$-optimal design (Bates \& Watts, 1988). Oliveira, Silva and Oliveira (1995) applied this concept for mass transfer processes controlled by internal diffusion under non-isothermal conditions (linearly increasing temperature profile), assuming an Arrhenius temperature dependence of the diffusion coefficient. These authors reported that both the accuracy and precision of the parameter estimates are maximum at intermediate values of the heating rate, the optimal heating rate being dependent on the parameter values. Cunha, Oliveira, Brandão and Oliveira (1997), on the other hand, have applied this concept to the Bigelow model under isothermal and non-isothermal conditions. They reported that, for linearly increasing temperature profiles, both the accuracy and precision of the parameter estimates are maximum at the lowest possible initial temperature and at the highest possible heating rate.

The main objective of this work was to establish the experimental conditions corresponding to the $D$-optimal design for systems described by the Arrhenius model for non-isothermal experimental plans with a linearly increasing temperature profile.

\section{Mathematical methods}

For any choice of the design variable (i.e., the independent variable, $t$ ) the size of the parameters joint confidence region is proportional to the Jacobian $\left|\left(\mathbf{F}^{\mathrm{T}} \mathbf{F}\right)\right|^{-1 / 2}$ of the derivative matrix $\mathbf{F}$ (where $\mathbf{F} \equiv\left[f_{i, j}\right]$, with $f_{i, j}=\partial \eta_{i} / \partial \theta_{j}$ evaluated at $t=t_{i}$, with $i$ ranging from 1 to $n ; \eta$ represents the system response and $\theta$ a kinetic parameter). Thus, a logical choice of the design criterion is to choose sampling points so that the size of 
this joint confidence region is minimised, that is, the determinant $D \equiv\left|\mathbf{F}^{\mathrm{T}} \mathbf{F}\right|$ should be maximised. It was found that, for several chemical reactions involving non-linear models, the optimal design for $n$ experiments (with $n>p$ ) consists of $n / p$ replications of the optimal sampling points for the case $n=p$ (Atkinson \& Hunter, 1968; Box, 1968, 1970). This has certainly simplified the evaluation of optimal designs. According to Box and Lucas (1959), in the case where $n=p$, the $D$-optimal design can be simplified from the maximisation of $D \equiv\left|\mathbf{F}^{\mathrm{T}} \mathbf{F}\right|$ to the maximisation of $\Delta \equiv$ $\bmod (|\mathbf{F}|)(\Delta$ denotes the modulus of the determinant of the matrix $\mathbf{F})$.

The changes of concentration over time for the firstorder Arrhenius model, and for a linearly increasing temperature profile, are given by

$\eta_{i}=\exp \left\{-k_{\text {ref }} \int_{0}^{t_{i}} \exp \left(-\frac{E_{\mathrm{a}}}{R}\left(\frac{1}{T_{0}+m t}-\frac{1}{T_{\text {ref }}}\right)\right) \mathrm{d} t\right\}$.

Integrating and rearranging Eq. (1), one obtains (see Appendix A)

$$
\begin{aligned}
\eta_{i}= & \exp \left\{-\left\{\frac { k _ { \text { ref } } } { m R } \left[R \left(\left(T_{0}+m t_{i}\right)\right.\right.\right.\right. \\
& \times \exp \left(\frac{E_{\mathrm{a}}}{R}\left(\frac{1}{T_{\text {ref }}}-\frac{1}{T_{0}+m t_{i}}\right)\right) \\
& \left.-T_{0} \exp \left(\frac{E_{\mathrm{a}}}{R}\left(\frac{1}{T_{\text {ref }}}-\frac{1}{T_{0}}\right)\right)\right) \\
& \left.\left.\left.+E_{\mathrm{a}} \exp \left(\frac{E_{\mathrm{a}}}{R T_{\text {ref }}}\right) I_{i}\right]\right\}\right\},
\end{aligned}
$$

where

$$
I_{i}=\int_{y_{0}}^{y_{i}} \frac{\mathrm{e}^{-y}}{y} \mathrm{~d} y, \quad y=\frac{E_{\mathrm{a}}}{R\left(T_{0}+m t\right)} .
$$

Differentiating Eq. (2) in relation to $k_{\text {ref }}$ and $E_{\mathrm{a}}$ :

$$
\begin{aligned}
\frac{\partial C_{i}}{\partial k_{\text {ref }}}= & -\left(\left\{C _ { 0 } \operatorname { e x p } \left\{-\left\{\frac { k _ { \text { ref } } } { m R } \left[R \left(\left(T_{0}+m t_{i}\right)\right.\right.\right.\right.\right.\right. \\
& \times \exp \left(\frac{E_{\mathrm{a}}}{R}\left(\frac{1}{T_{\text {ref }}}-\frac{1}{T_{0}+m t_{i}}\right)\right) \\
& \left.-T_{0} \exp \left(\frac{E_{\mathrm{a}}}{R}\left(\frac{1}{T_{\text {ref }}}-\frac{1}{T_{0}}\right)\right)\right) \\
& \left.\left.\left.\left.\left.+E_{\mathrm{a}} \exp \left(\frac{E_{\mathrm{a}}}{R T_{\text {ref }}}\right) I_{i}\right]\right\}\right\}\right\} / m R\right) \\
& \times\left[R \left(\left(T_{0}+m t_{i}\right) \exp \left(\frac{E_{\mathrm{a}}}{R}\left(\frac{1}{T_{\text {ref }}}-\frac{1}{T_{0}+m t_{i}}\right)\right)\right.\right. \\
& \left.-T_{0} \exp \left(\frac{E_{\mathrm{a}}}{R}\left(\frac{1}{T_{\text {ref }}}-\frac{1}{T_{0}}\right)\right)\right) \\
& \left.+E_{\mathrm{a}} \exp \left(\frac{E_{\mathrm{a}}}{R T_{\text {ref }}}\right) I_{i}\right]
\end{aligned}
$$

$$
\begin{aligned}
\frac{\partial C_{i}}{\partial E_{\mathrm{a}}}= & -\left(\left\{C _ { 0 } k _ { \text { ref } } \operatorname { e x p } \left\{-\left\{\frac { k _ { \text { ref } } } { m R } \left[R \left(\left(T_{0}+m t_{i}\right)\right.\right.\right.\right.\right.\right. \\
& \times \exp \left(\frac{E_{\mathrm{a}}}{R}\left(\frac{1}{T_{\text {ref }}}-\frac{1}{T_{0}+m t_{i}}\right)\right) \\
& \left.-T_{0} \exp \left(\frac{E_{\mathrm{a}}}{R}\left(\frac{1}{T_{\text {ref }}}-\frac{1}{T_{0}}\right)\right)\right) \\
& \left.\left.\left.\left.\left.+E_{\mathrm{a}} \exp \left(\frac{E_{\mathrm{a}}}{R T_{\text {ref }}}\right) I_{i}\right]\right\}\right\}\right\} / m R T_{\text {ref }}\right) \\
& \times \exp \left(\frac{E_{\mathrm{a}}}{R T_{\text {ref }}}\right)\left[\left(T_{0}+m t_{i}\right) \exp \left(\frac{E_{\mathrm{a}}}{R\left(T_{0}+m t_{i}\right)}\right)\right. \\
& \left.-T_{0} \exp \left(\frac{E_{\mathrm{a}}}{R T_{0}}\right)+\left(T_{\text {ref }}+\frac{E_{\mathrm{a}}}{R}\right) I_{i}\right] .
\end{aligned}
$$

These equations may be simplified if written in terms of $\eta_{i}$

$\frac{\partial C_{i}}{\partial k_{\text {ref }}}=\frac{C_{0} \eta_{i} \ln \left(\eta_{i}\right)}{k_{\text {ref }}}$,

$\frac{\partial C_{i}}{\partial E_{\mathrm{a}}}=-\frac{C_{0} k_{\mathrm{ref}} \eta_{i}}{m R T_{\text {ref }}} \exp \left(\frac{E_{\mathrm{a}}}{R T_{\text {ref }}}\right) X_{i}$,

where $X_{i}$ is a dummy variable used for further condensed notation

$$
\begin{aligned}
X_{i}= & {\left[\left(T_{0}+m t_{i}\right) \exp \left(\frac{E_{\mathrm{a}}}{R\left(T_{0}+m t_{i}\right)}\right)\right.} \\
& \left.-T_{0} \exp \left(\frac{E_{\mathrm{a}}}{R T_{0}}\right)+\left(T_{\text {ref }}+\frac{E_{\mathrm{a}}}{R}\right) I_{i}\right] .
\end{aligned}
$$

The determinant of the matrix of the derivatives of Eq. (2) in order to the model parameters at the two sampling times, $\Delta$, may be calculated from Eqs. (4)-(7), yielding

$$
\begin{aligned}
\Delta= & \bmod \left(\left|\begin{array}{ll}
\frac{\partial C_{1}}{\partial k_{\text {ref }}} & \frac{\partial C_{1}}{\partial E_{\mathrm{a}}} \\
\frac{\partial C_{2}}{\partial k_{\text {ref }}} & \frac{\partial C_{2}}{\partial E_{\mathrm{a}}}
\end{array}\right|\right)=\bmod \left(\frac{C_{0}^{2} \eta_{1} \ln \left(\eta_{1}\right) \eta_{2} \ln \left(\eta_{2}\right)}{m R T_{\text {ref }}}\right. \\
& \left.\times \exp \left(\frac{E_{\mathrm{a}}}{R T_{\text {ref }}}\right)\left[\frac{X_{1}}{\ln \left(\eta_{1}\right)}-\frac{X_{2}}{\ln \left(\eta_{2}\right)}\right]\right) .
\end{aligned}
$$

Due to the complexity of this equation, numerical optimisation was performed (using Mathematica ${ }^{\circledast}$ for Windows-3.0, enhanced version (Wolfram, 1996), which applies a steepest descent minimisation method).

\section{Results and discussion}

To have a first insight into the behaviour of the nonisothermal first-order Arrhenius model, the $D$-optimal design was numerically computed for different experimental conditions, with $T_{0}$ ranging from $0^{\circ} \mathrm{C}$ to $110^{\circ} \mathrm{C}$ and $m$ ranging from $1^{\circ} \mathrm{C} \mathrm{min}-1$ to $100^{\circ} \mathrm{C} \mathrm{min}{ }^{-1}$. A design efficiency was defined, $\zeta=\Delta_{\max } / \Delta_{\text {opt }} \times 100$, where $\Delta_{\max }$ is the maximum value of the determinant for fixed $m$ and $T_{0}$ conditions (that will be referred to as 
sub-optimal design), and $\Delta_{\mathrm{opt}}$ is the optimum value of the determinant within the range of experimental conditions tested. These calculations were based on a given set of parameters: $k_{121^{\circ} \mathrm{C}}=0.048 \mathrm{~min}^{-1}$ and $E_{\mathrm{a}}=43 \mathrm{~kJ} /$ mol. These values are equivalent to the $D_{\text {ref }}$ and $z$ values used by Cunha et al. (1997) for the Bigelow model under non-isothermal conditions $\left(D_{121^{\circ} \mathrm{C}}=48 \mathrm{~min}\right.$ and $z=$ $\left.59^{\circ} \mathrm{C}\right)$. They were calculated as $k_{121^{\circ} \mathrm{C}}=\ln (10) / D_{121^{\circ} \mathrm{C}}$ and $E_{\mathrm{a}}=R\left(T_{\text {ref }}-z\right) T_{\text {ref }} \ln (10) / z$ (Lund, 1975). The results are depicted in Fig. 1, where it can be seen that a very good precision can be obtained when the initial temperature is low. For high initial temperatures, increasing the heating rate significantly improves the precision of sub-optimal designs, but very high heating rates would be required to reach efficiency values above $90 \%$. For low $T_{0}$ values the heating rate does not affect so much the efficiency of the design, and curiously Fig. 1 shows that $\zeta$ actually decreases as $m$ increases. A more detailed analysis showed that for each initial temperature the design efficiency has a maximum for intermediate $m$ values, as illustrated in Fig. 2.

This behaviour is different from the observed for the Bigelow model, where the higher the heating rate, the higher is the design efficiency (Cunha et al., 1997). It was further observed that, for each $T_{0}$, the heating rate at which the design efficiency is maximum corresponds to the sampling times required to reach a fractional concentration of $0.70322 \ldots$ and $0.19245 \ldots$, being the cologarithm of the product of the fractional concentrations $\eta_{1}$ and $\eta_{2}$ equal to $1 / e^{2}$ (see Fig. 3). These values are identical to those obtained for the Bigelow model under non-isothermal conditions (Cunha et al., 1997)

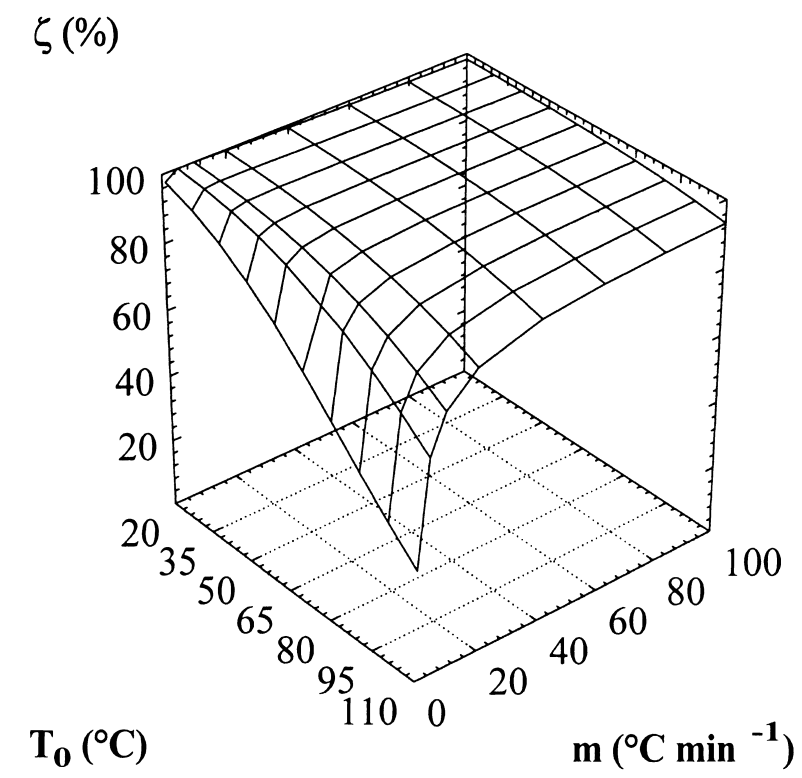

Fig. 1. Influence of the initial temperature $\left(T_{0}\right)$ and of the heating rate $(m)$ on the design efficiency $(\zeta)$ for the first-order Arrhenius model under non-isothermal conditions $\left(k_{\mathrm{ref}}=0.048 \mathrm{~min}^{-1}, E_{\mathrm{a}}=43 \mathrm{~kJ} \mathrm{~mol}^{-1}\right.$ and $T_{\text {ref }}=121^{\circ} \mathrm{C}$ ).

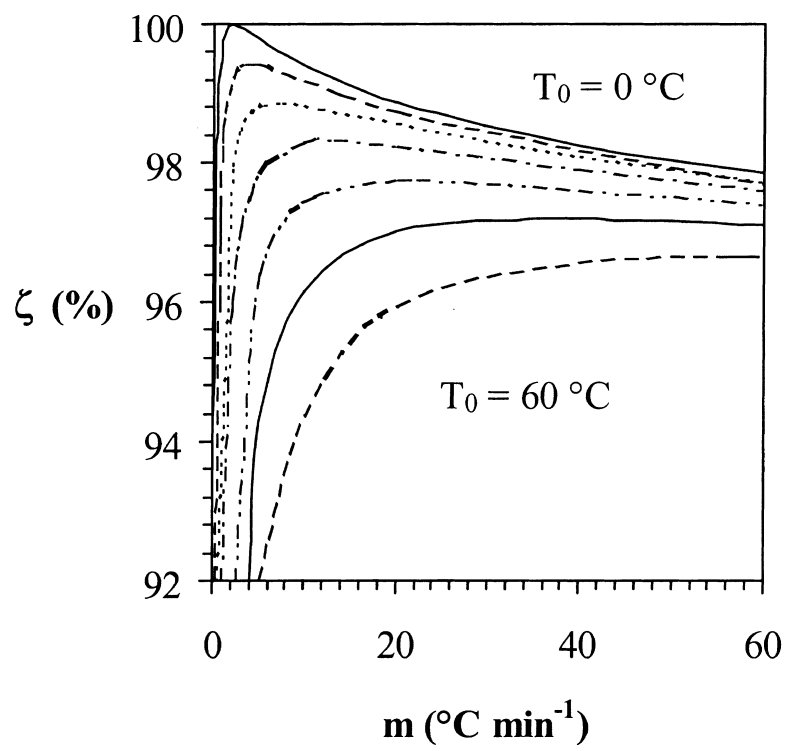

Fig. 2. Influence of the heating rate $(m)$ on the design efficiency $(\zeta)$ for the first-order Arrhenius model under non-isothermal conditions $\left(k_{\text {ref }}=0.048 \mathrm{~min}^{-1}, E_{\mathrm{a}}=43 \mathrm{~kJ} \mathrm{~mol}^{-1}\right.$ and $\left.T_{\text {ref }}=121^{\circ} \mathrm{C}\right)$.

and to the Weibull probabilistic model under isothermal conditions (Cunha, Oliveira \& Oliveira, 1998). Furthermore, when increasing the values of $T_{0}$, the heating rates required to achieve maximum efficiency increase

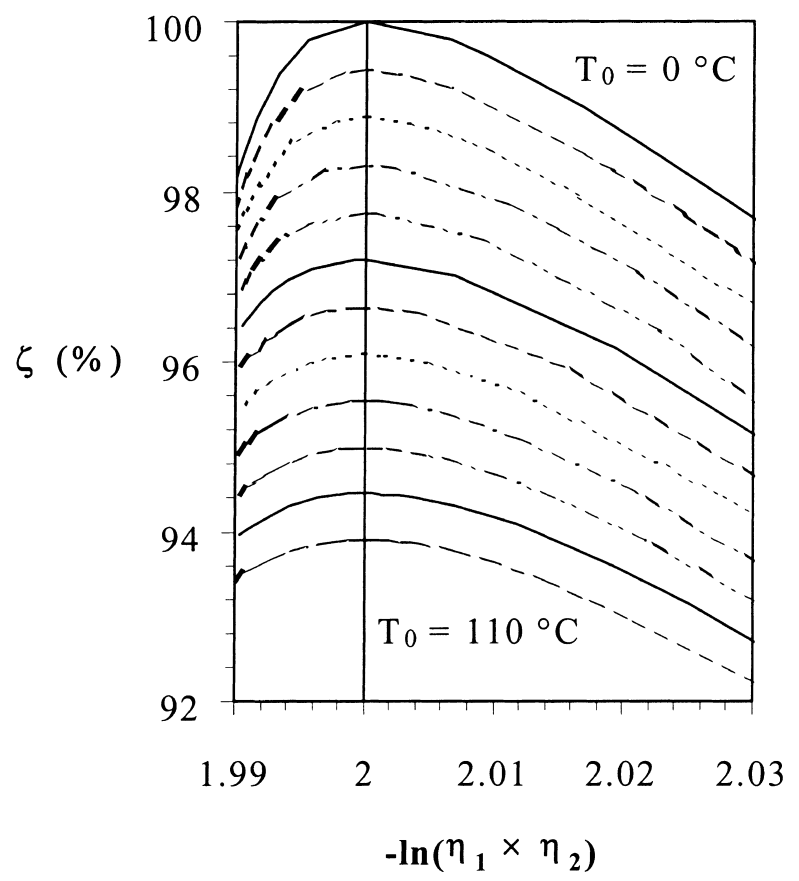

Fig. 3. Dependence of the design efficiency $(\zeta)$ for the first-order Arrhenius model under non-isothermal conditions on the fractional concentrations $\eta_{1}$ and $\eta_{2}$, for different values of the initial temperature $\left(T_{0}\right)\left(k_{\mathrm{ref}}=0.048 \mathrm{~min}^{-1}, E_{\mathrm{a}}=43 \mathrm{~kJ} \mathrm{~mol}^{-1}\right.$ and $\left.T_{\text {ref }}=121^{\circ} \mathrm{C}\right)$. Each value $\eta_{1} \times \eta_{2}$ corresponds to the optimal sampling times at a different heating rate. 


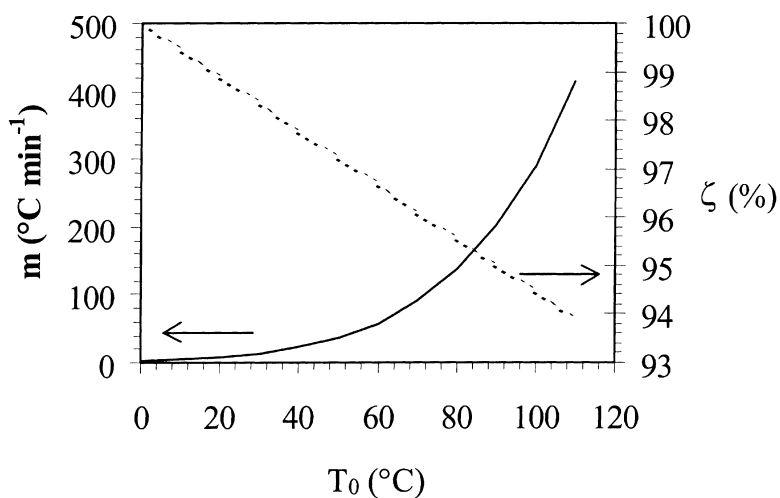

Fig. 4. Dependence of the design efficiency $(\zeta)$ for the first-order Arrhenius model under non-isothermal conditions and of the corresponding optimal heating rate $(\mathrm{m})$ on the initial temperature $\left(T_{0}\right)$ $\left(k_{\text {ref }}=0.048 \mathrm{~min}^{-1}, E_{\mathrm{a}}=43 \mathrm{~kJ} \mathrm{~mol}^{-1}\right.$ and $\left.T_{\text {ref }}=121^{\circ} \mathrm{C}\right)$.

exponentially, whereas the efficiency of the design decreases linearly (see Fig. 4).

\section{Case study}

To clarify the application of these concepts in food research, a case study is provided, using data from literature. Pinheiro-Torres and Oliveira (1999) estimated the kinetic parameters of acid hydrolysis of sucrose in a range of $\mathrm{pH}$, under non-isothermal conditions, assuming that the kinetics followed a first-order Arrhenius model. The experiments were initiated at a temperature of $50^{\circ} \mathrm{C}$ and the heating rate varied between $1.43^{\circ} \mathrm{C}$ $\min ^{-1}$ and $2.39^{\circ} \mathrm{C} \min ^{-1}$, depending on the $\left[\mathrm{H}^{+}\right]$concentration (some of the experimental conditions are summarised in Table 1). The activation energy of the process was found to be independent of $\mathrm{pH}$ and equal to $98 \mathrm{~kJ} / \mathrm{mol}$, whereas the rate constant at a reference temperature of $77^{\circ} \mathrm{C}$ was reported to increase exponentially with $\left[\mathrm{H}^{+}\right]: k_{77^{\circ} \mathrm{C}}=0.098 \exp \left(21.6\left[\mathrm{H}^{+}\right]\right) \mathrm{min}^{-1}$.

For each set of conditions summarised in Table 1, the optimal sampling times were computed and the corre-

Table 1

Experimental conditions used by Pinheiro-Torres and Oliveira (1999) in the study of the kinetics of acid hydrolysis of sucrose using a linearly increasing temperature profile starting at $50^{\circ} \mathrm{C}$, and estimated rate constants, a reference temperature of $77^{\circ} \mathrm{C}$

\begin{tabular}{lll}
\hline$\left[\mathrm{H}^{+}\right]\left(\mathrm{mol} \mathrm{l}^{-1}\right)$ & $m\left({ }^{\circ} \mathrm{C} \mathrm{min}^{-1}\right)$ & $k_{77^{\circ} \mathrm{C}}\left(\mathrm{min}^{-1}\right)$ \\
\hline 0.0376 & 1.570 & 0.2208 \\
0.0047 & 1.524 & 0.1085 \\
0.0521 & 1.430 & 0.3020 \\
0.0631 & 1.688 & 0.3830 \\
0.0744 & 1.559 & 0.4888 \\
0.0803 & 1.590 & 0.5553 \\
0.0998 & 1.879 & 0.8461 \\
0.1185 & 1.826 & 1.2672 \\
0.1253 & 2.388 & 1.4677 \\
\hline
\end{tabular}

sponding value of $\Delta$ was considered as $\Delta_{\max }$. The optimal heating rate for the initial temperature used $\left(50^{\circ} \mathrm{C}\right)$ and the corresponding optimal sampling times were also computed, the corresponding $\Delta$ value being considered as $\Delta_{\text {opt }}$. As can be observed on Fig. 5, the optimal heating rates increase linearly with the values of the reaction rate constants, reaching values that are physi-

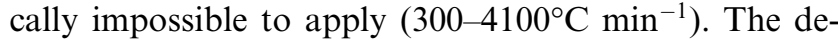
sign efficiency is shown in Fig. 6, as a function of the rate constant. As expected, the design efficiency decreases as the heating rate increases, which implies that the experimental conditions applied by Pinheiro-Torres and Oliveira (1999) would inherently lead to a lower precision at the higher acid concentrations tested. As a matter of fact, this may be observed in the results reported by Pinheiro-Torres and Oliveira (1999), as the

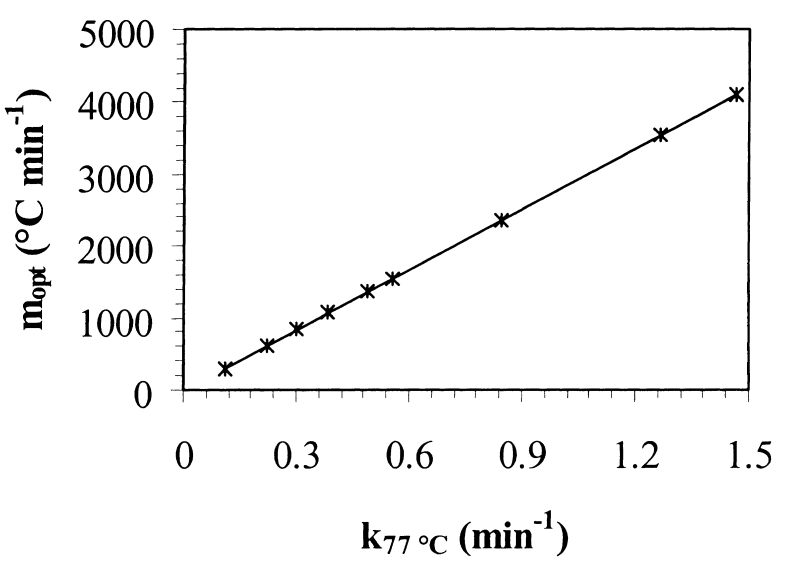

Fig. 5. Optimal heating rates $\left(m_{\mathrm{opt}}\right)$ for the model parameter estimation of the acid hydrolysis of sucrose under linearly increasing temperature, with an initial temperature of $50^{\circ} \mathrm{C}\left(T_{\text {ref }}=77^{\circ} \mathrm{C}\right.$, data from PinheiroTorres and Oliveira (1999)). The line represents a linear fit $\left(m_{\mathrm{opt}}=2798.7 \times k_{77^{\circ} \mathrm{C}}, R^{2}=1\right)$.

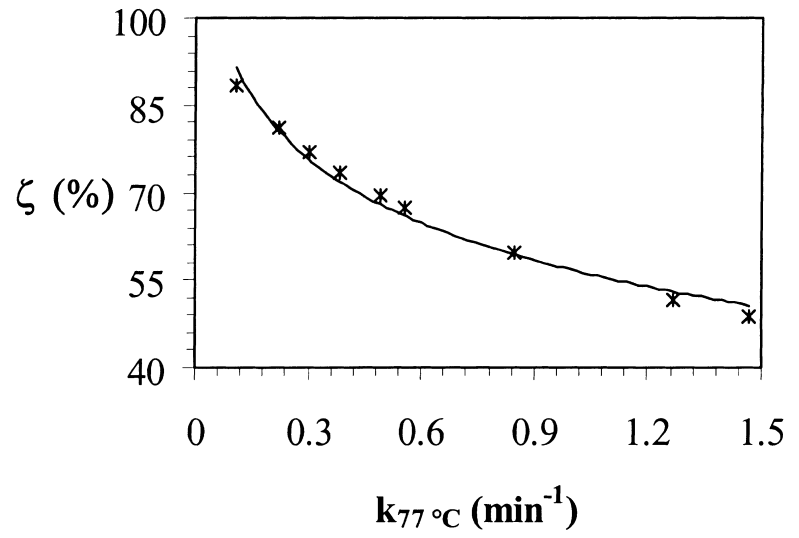

Fig. 6. Dependence of the design efficiency ( $\zeta$ ) for the estimation of the model parameters of the non-isothermal acid hydrolysis of sucrose on $k_{77^{\circ} \mathrm{C}}\left(T_{0}=50^{\circ} \mathrm{C}, m\right.$ values given in Fig. 5). The line represents a logarithmic fit $\left(\zeta=-15.724 \times \ln \left(k_{77^{\circ} \mathrm{C}}\right)+56.725, R^{2}=0.9823\right)$. 
Table 2

Experimental conditions determined according to the $D$-optimal design criterion for the joint estimation of the reaction rate constants $\left(k_{77^{\circ}} \mathrm{C}\right)$ and of the activation energy of the non-isothermal acid hydrolysis of sucrose with a fixed heating rate of $2^{\circ} \mathrm{C} \min ^{-1}\left(T_{0}=50^{\circ} \mathrm{C}\right)$

\begin{tabular}{|c|c|c|c|c|c|c|}
\hline$k_{77^{\circ} \mathrm{C}}\left(\min ^{-1}\right)$ & $t_{1}(\min )$ & $t_{2}(\min )$ & $T_{1}\left({ }^{\circ} \mathrm{C}\right)$ & $T_{2}\left({ }^{\circ} \mathrm{C}\right)$ & $m_{\text {optimal }}\left({ }^{\circ} \mathrm{C} \min ^{-1}\right)$ & $\zeta(\%)$ \\
\hline 0.1085 & 12.18 & 19.43 & 74.4 & 88.9 & 303 & 88.46 \\
\hline 0.2208 & 9.31 & 15.96 & 68.6 & 81.9 & 618 & 81.09 \\
\hline 0.3020 & 8.16 & 14.51 & 66.3 & 79.0 & 845 & 76.94 \\
\hline 0.3830 & 7.33 & 13.44 & 64.7 & 76.9 & 1072 & 73.41 \\
\hline 0.4888 & 6.53 & 12.37 & 63.1 & 74.7 & 1368 & 69.47 \\
\hline 0.5553 & 6.13 & 11.82 & 62.3 & 73.6 & 1554 & 67.29 \\
\hline 0.8461 & 4.91 & 10.09 & 59.8 & 70.2 & 2368 & 59.56 \\
\hline 1.2672 & 3.89 & 8.53 & 57.8 & 67.1 & 3546 & 51.62 \\
\hline 1.4677 & 3.56 & 7.99 & 57.1 & 66.0 & 4108 & 48.66 \\
\hline
\end{tabular}

confidence intervals for the reaction rate estimates obtained from the experiments performed at higher acid concentration are clearly larger than those obtained for the lower acid concentrations. However, this problem cannot be overcome by the application of the optimal design, because as earlier-mentioned, the required heating rates would be impracticable. If one wants to maintain the initial temperature at $50^{\circ} \mathrm{C}$, the design might be improved by using a constant heating rate but taking more replicates as $\left[\mathrm{H}^{+}\right]$increases. The optimal sampling times, according to the $D$-optimal design criterion, for $T_{0}=50^{\circ} \mathrm{C}$ and $m=2^{\circ} \mathrm{C} \mathrm{min}^{-1}$ are summarised in Table 2, as well as the corresponding design efficiency. Fig. 7 shows the number of replicates required for each $\left[\mathrm{H}^{+}\right]$value, so that all the experiments would yield the same generalised variance of the parameters (determined as the inverse of the fractional design efficiency (Atkinson \& Donev, 1992)). It can be seen that the number of required replicates increases linearly with

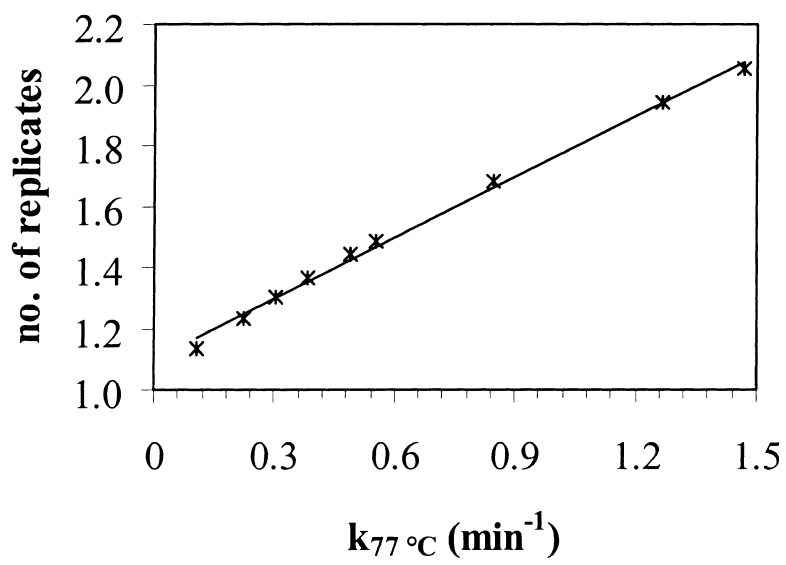

Fig. 7. Number of replicates needed to obtain the maximum generalised variance of the model parameters of the non-isothermal acid hydrolysis of sucrose, using a fixed heating rate of $2^{\circ} \mathrm{C} \min ^{-1}$, as a function of $k_{77^{\circ} \mathrm{C}}\left(T_{0}=50^{\circ} \mathrm{C}\right.$ ). The line represents a linear fit (no. of replicates $\left.=0.6677 \times k_{77^{\circ} \mathrm{C}}+1.0952, R^{2}=0.9961\right)$.
$\left[\mathrm{H}^{+}\right]$and at the highest concentration tested the number of replicates should be approximately twice those at the lowest concentration. Another alternative to improve parameter estimation would be to lower the initial temperature. It was found that if $T_{0}$ was lowered to $20^{\circ} \mathrm{C}$, the optimal heating rates would range from $7^{\circ} \mathrm{C}$ $\mathrm{min}^{-1}$ to $100^{\circ} \mathrm{C} \mathrm{min}^{-1}$. As an example, for $k_{77^{\circ} \mathrm{C}}=0.0047$ $\mathrm{min}^{-1}$, the optimal sampling design would correspond to a heating rate of $7.6^{\circ} \mathrm{C} \mathrm{min}-1$ and to sampling times $t_{1}=8.7 \mathrm{~min}$ and $t_{2}=10.9 \mathrm{~min}$, covering a range of temperatures from $20^{\circ} \mathrm{C}$ to $103^{\circ} \mathrm{C}$.

\section{Conclusions}

For improving the estimation of the parameters of the first-order Arrhenius model from experiments with linearly increasing temperature profiles, experiments should be started at the lowest possible temperature and, for each initial temperature, there is an optimal heating rate. This heating rate is often too high to be feasible, implying that experiments have to be conducted at a lower practicable heating rate. In this situation the experiments should be replicated in order to guarantee estimates precision and the number of replicates required may be evaluated from the design efficiency.

If both $T_{0}$ and $m$ are fixed at their optimal values, the optimal sampling times correspond to the fractional concentrations $\eta_{1}=0.70322 \ldots$ and $\eta_{2}=0.19245 \ldots$, with $\eta_{1} \eta_{2}=1 / e^{2}$, as earlier found for the Bigelow model.

\section{Acknowledgements}

The first author acknowledges financial support from Fundação para a Ciência e a Tecnologia (FCT) through "Sub-programa Ciência e Tecnologia do $2^{\circ}$ Quadro Comunitário de Apoio". 


\section{Appendix A}

Considering the equation that describes changes of concentration over time for the first-order Arrhenius model, and for a linearly increasing temperature profile

$\eta_{i}=\exp \left\{-k_{\text {ref }} \int_{0}^{t_{i}} \exp \left(-\frac{E_{\mathrm{a}}}{R}\left(\frac{1}{T_{0}+m t}-\frac{1}{T_{\text {ref }}}\right) \mathrm{dt}\right)\right\}$.

Let

$y=\frac{E_{\mathrm{a}}}{R\left(T_{0}+m t\right)}$.

Then

$t=\frac{1}{m}\left(\frac{E_{\mathrm{a}}}{R y}-T_{0}\right)$,

$\mathrm{d} t=-\frac{E_{\mathrm{a}}}{m R y^{2}} \mathrm{~d} y$.

Substituting Eqs. (A.3) and (A.4) in Eq. (A.1) and rearranging

$\eta_{i}=\exp \left\{\left(\frac{E_{\mathrm{a}} k_{\mathrm{ref}} \exp \left(E_{\mathrm{a}} / R T_{\mathrm{ref}}\right)}{m R} \int_{y_{0}}^{y_{i}} \frac{\mathrm{e}^{-y}}{y^{2}} \mathrm{~d} y\right)\right\}$,

where

$y_{i}=\frac{E_{\mathrm{a}}}{R\left(T_{0}+m t_{i}\right)} \quad$ and $\quad y_{0}=\frac{E_{\mathrm{a}}}{R T_{0}}$.

Noting that

$$
\begin{aligned}
\int_{\mathrm{a}}^{b} u(y) \frac{\mathrm{d} v(y)}{\mathrm{d} y} \mathrm{~d} y= & u(b) v(b)-u(a) v(a) \\
& -\int_{\mathrm{a}}^{b} \frac{\mathrm{d} u(y)}{\mathrm{d} y} v(y) \mathrm{d} y
\end{aligned}
$$

and considering

$u(y)=\mathrm{e}^{-y} ; \quad \frac{\mathrm{d} u(y)}{\mathrm{d} y}=-\mathrm{e}^{-y}$,

$v(y)=\frac{1}{y} ; \quad \frac{\mathrm{d} v(y)}{\mathrm{d} y}=-\frac{1}{y^{2}}$.

Eq. (A.5) can be integrated yielding

$\eta_{i}=\exp \left\{-\left[\frac{E_{\mathrm{a}} k_{\mathrm{ref}} \exp \left(E_{\mathrm{a}} / R T_{\mathrm{ref}}\right)}{m R}\left(\frac{\mathrm{e}^{-y_{i}}}{y_{i}}-\frac{\mathrm{e}^{-y_{0}}}{y_{0}}+I_{i}\right)\right]\right\}$,

where

$I_{i}=\int_{y_{0}}^{y_{i}} \frac{\mathrm{e}^{-y}}{y^{2}} \mathrm{~d} y$.

Substituting Eq. (A.2) in Eq. (A.10) and re-arranging

$$
\begin{aligned}
\eta_{i}= & \exp \left\{-\left\{\frac { k _ { \text { ref } } } { m R } \left[R \left(\left(T_{0}+m t_{i}\right)\right.\right.\right.\right. \\
& \times \exp \left(\frac{E_{\mathrm{a}}}{R}\left(\frac{1}{T_{\text {ref }}}-\frac{1}{\left(T_{0}+m t_{i}\right)}\right)\right) \\
& \left.-T_{0} \exp \left(\frac{E_{\mathrm{a}}}{R}\left(\frac{1}{T_{\text {ref }}}-\frac{1}{T_{0}}\right)\right)\right) \\
& \left.\left.\left.+E_{a} \exp \left(\frac{E_{\mathrm{a}}}{R T_{\text {ref }}}\right) I_{i}\right]\right\}\right\} .
\end{aligned}
$$

\section{References}

Atkinson, A. C., \& Donev, A. N. (1992). Optimum experimental designs (p. 42). Oxford: Oxford University Press.

Atkinson, A. C., \& Hunter, W. G. (1968). The design of experiments for parameter estimation. Technometrics, 10, 271-289.

Bates, D. M., \& Watts, D. G. (1988). Nonlinear regression analysis and its applications (pp. 121-127). New York: Wiley.

Box, M. J. (1968). The occurrence of replications in optimal designs of experiments to estimate parameters in non-linear models. Journal of the Royal Statistical Society, Series B, 30, 290-320.

Box, M. J. (1970). Some experiences with a nonlinear experimental design criterion. Technometrics, 12, 569-589.

Box, G. E. P., \& Lucas, H. L. (1959). Design of experiments for nonlinear situations. Biometrika, 46, 77-90.

Brandão, T. R. S., \& Oliveira, F. A. R. (1997). The influence of the temperature increase rate on the accuracy of diffusion parameters estimated under non-isothermal conditions. International Journal of Food Science and Technology, 32, 63-72.

Cunha, L. M., Oliveira, F. A. R., Brandão, T. R. S., \& Oliveira, J. C. (1997). Optimal experimental design for estimating the kinetic parameters of the Bigelow model. Journal of Food Engineering, 33, 111-128.

Cunha, L. M., Oliveira, F. A. R., \& Oliveira, J. C. (1998). Optimal experimental design for estimating the kinetic parameters of processes described by the Weibull probability distribution function. Journal of Food Engineering, 37, 175-191.

David, J. R. D., \& Merson, R. L. (1990). Kinetic parameters for inactivation of Bacillus stearothermophilus at high temperatures. Journal of Food Science, 55, 488-493.

Holdsworth, S. D. (1985). Optimization of thermal processing - a review. Journal of Food Engineering, 4, 89-111.

Jonsson, U., Snygg, B. G., Härnulv, B. G., \& Zacrisson, T. (1977). Testing two models for the temperature dependence of the heat inactivation rate of Bacillus stearothermophilus spores. Journal of Food Science, 42, 1251-1252 (and p. 1263).

Lund, D. B. (1975). Heat processing. In M. Karel, O. R. Fennemam, \& D. B. Lund, Principles of food science. Part II. Physical principles of food preservation. New York: Marcel Dekker.

Manji, B., \& van de Voort, F. R. (1985). Comparison of two models for process holding time calculations: convection system. Journal of Food Protection, 48, 359-362.

Moreira, L. A., Oliveira, F. A. R., Silva, T. R., \& Oliveira, J. C. (1993). Development of a non-isothermal method for determination of diffusional parameters. International Journal of Food Science and Technology, 28, 575-586.

Nunes, R. V., Rhim, J. W., \& Swartzel, K. R. (1991). Kinetic parameter evaluation with linearly increasing temperature profiles: integral methods. Journal of Food Science, 56, 1433-1437.

Ocio, M. J., Fernandez, P. S., Alvarruiz, A., \& Martínez, A. (1994). Comparison of TDT and Arrhenius models for rate constant 
inactivation predictions of Bacillus stearothermophilus heated in mushroom-alginate substrate. Letters in Applied Microbiology, 19, 114-117.

Oliveira, F. A. R., Silva, T. R., \& Oliveira, J. C. (1995). Optimal experimental design for estimation of mass diffusion parameters using non-isothermal conditions. In Proceedings of the First International Symposium on Mathematical Modelling and Simulation in Agriculture \& Bio-Industries of IMACS/IFAC, 9-12 May 1995, Brussels, Belgium.

Pinheiro-Torres, A., \& Oliveira, F. A. R. (1999). Application of the acid hydrolysis of sucrose as a temperature indicator in continuous thermal processes. Journal of Food Engineering, 40, 181-188.

Ramaswamy, H. S., van de Voort., \& Ghazala, S. (1989). An analysis of TDT and Arrhenius methods for handling process and kinetic data. Journal of Food Science, 54, 1322-1326.

Rhim, J. W., Nunes, R. V., Jones, V. A., \& Swartzel, K. R. (1989a). Determination of kinetic parameters using linearly increasing temperatures. Journal of Food Science, 54, 446-450.
Rhim, J. W., Nunes, R. V., Jones, V. A., \& Swartzel, K. R. (1989b). Kinetics of color change of grape juice generated using linearly increasing temperatures. Journal of Food Science, 54, 776-777.

Rogers, A. R. (1963). An accelerated storage test with programmed temperature rise. Journal of Pharmacy and Pharmacology, 15, 101T-105T (Supplement, Transactions of the British Pharmaceutical Conference, Centenary Meeting London).

Saraiva, J., Oliveira, J. C., Hendrickx, M., Oliveira, F. A. R., \& Tobback, P. (1996). Analysis of the inactivation kinetics of freezedried $\alpha$-amylase from Bacillus amyloliquefaciens at different moisture contents. Lebensmittel Wissenchaft und Technologie, 29, 260266.

Van Loey, A. (1996). Enzymic time temperature integrators for the quantification of thermal processes in terms of food safety. Ph.D. Thesis, Katholieke Universiteit Leuven, Belgium.

Wolfram, S. (1996). Mathematica. A system for doing mathematics by computer - version 3.0. Reading, MA: Addison-Wesley. 